\title{
Prevalence and Risk Factors for Self-reported Sexually Transmitted Infections among Adults in the Diepsloot Informal Settlement, Johannesburg, South Africa
}

\author{
Tariro J Basera ${ }^{1,5}$, Simbarashe Takuva ${ }^{2,3}$, Keith Muloongo ${ }^{4}$, Ndumiso Tshuma ${ }^{4}$ and Peter S Nyasulu N $^{1,5 *}$ \\ ${ }^{1}$ School of Health Sciences, Monash University, 144 Peter Road, Ruimsig, Johannesburg, South Africa \\ ${ }^{2}$ Perinatal HIV Research Unit, Department of Internal Medicine, School of Clinical Medicine, Faculty of Health Sciences, University of the Witwatersrand, Johannesburg, \\ South Africa \\ ${ }^{3}$ Centre for HIV and Sexually Transmitted Infections, National Institute for Communicable Diseases, NHLS, Johannesburg, South Africa \\ ${ }^{4}$ Community AIDS Response, 26 Grant Avenue, Norwood, Johannesburg, South Africa \\ ${ }^{5}$ Department of Epidemiology and Biostatistics, School of Public Health, Faculty of Health Sciences, University of the Witwatersrand, Johannesburg, South Africa
}

\begin{abstract}
Background: Sexually transmitted infections (STIs) are a significant cause of morbidity among sexually active adults with multiple consequences including enhancing HIV transmission.

Objective: To determine the prevalence of self-reported sexually transmitted infections and associated risk factors among adults in Diepsloot informal settlement, Johannesburg, South Africa.

Design: This is a cross sectional study involving secondary analysis of data collected in a survey among adults living in Diepsloot in 2013. Data from 3953 respondents was analysed. Univariable and multivariable logistic regression modelling was used to estimate the odds ratio $(\mathrm{OR})$ and $95 \%$ confidence interval $(\mathrm{Cl})$ of the association between selfreported STI status and socio-demographic and clinical characteristics.
\end{abstract}

Results: Of the 3953 participants, $2481(62.8 \%)$ were female. Self-reported prevalence of STIs was $20.4 \%$ $(\mathrm{n}=808)$. Among the study participants, $815(25.9 \%)$ people were HIV positive and of these $19.9 \%$ reported an STI. Being single [Odds Ratio (OR) $1.82,(95 \% \mathrm{Cl} 1.08,3.05)]$, prior exposure to gender based violence or sexual assault (OR 2.25, 95\% Cl 1.39, 3.63), alcohol use (OR 1.50, 95\% Cl 1.04, 2.16), and having not utilised healthcare services in the past 2 years $(\mathrm{OR} 2.30,95 \% \mathrm{Cl} 1.44,3.68)$ were associated with increased odds of self-reporting an STI. HIV negative status was associated with reduced odds of self-reporting an $\mathrm{STI}(\mathrm{OR}=0.26,95 \% \mathrm{Cl} 0.14,0.50)$

Conclusion: The estimated prevalence of self-reported STIs among adults aged 20 to 82 years in Diepsloot, indicates a substantial burden of STIs in this population. The close connection between HIV status, history of gender based violence/sexual assault and utilisation of healthcare services underscore the need to scale up behavioural interventions coupled with targeted screening of at risk populations to simultaneously reduce the occurrence of genderbased violence and prevent the transmission of STIs including HIV.

Keywords: Sexually transmitted infections; HIV/AIDS; Diepsloot; Informal settlement; South Africa

\section{Introduction}

Sexually transmitted infections (STIs) remain a growing public health issue accounting for significant morbidity worldwide. In 2012, the World Health Organization (WHO) estimated there were 498.9 million cases of treatable STIs occurring among adults aged 15-49 years globally. The significance of STIs is profound in Africa which reported over 19\% of STIs (92.6 million cases) [1]. The commonly reported STIs in South Africa are syphilis, gonorrhoea, chlamydia, herpes simplex virus type 2 and trichomoniasis [2]. Prevention and early treatment of STIs is a high public health priority in South Africa which is reflected in the HIV/AIDS/STI Strategic Plan for South Africa 2012-2016 of the National Department of Health [3].

The burden of disease attributed to sexually transmitted infections (STIs) has aggravated the HIV epidemic in some regions. It is estimated that the probability of HIV transmission per sexual contact is $6 \%$ if either partner is experiencing a STI. This compares with HIV transmission rates in the absence of STIs of $0.2 \%[4,5]$. According to the WHO, in 2013 about 5.26 million people were reported to be living with HIV/ AIDS in South Africa [1]. In South Africa, the proportion of new HIV infections in adults that were attributable to curable STIs reduced from $39 \%$ in 1990 to $14 \%$ in 2010 , while the proportion of new infections attributable to genital herpes increased from $23 \%$ to $29 \%$ [4]. Sexually transmitted infections increase the efficiency of HIV transmission by increasing both the infectiousness of and the susceptibility to HIV infection [6]. In addition, STIs have been associated with adverse pregnancy outcomes, pelvic inflammatory disease, cervical cancer, multiple reproductive sequelae and infertility [7].

Commonly known risk factors for STIs include inconsistent condom use, having multiple sex partners, female gender, being single and among HIV positive people, not initiating antiretroviral treatment (ART) [8,9].

*Corresponding author: Peter S Nyasulu, School of Health Sciences, Monash University, 144 Peter Rd, Roodepoort, 1724, South Africa, Tel: +27119504287; E-mail: peter.nyasulu@monash.edu

Received January 02, 2016; Accepted January 27, 2016; Published January 30, 2016

Citation: Basera TJ, Takuva S, Muloongo K, Tshuma N, Nyasulu PS (2016) Prevalence and Risk Factors for Self-reported Sexually Transmitted Infections among Adults in the Diepsloot Informal Settlement, Johannesburg, South Africa. J AIDS Clin Res 7: 539. doi:10.4172/2155-6113.1000539

Copyright: ( $\odot 2016$ Basera TJ, et al. This is an open-access article distributed unde the terms of the Creative Commons Attribution License, which permits unrestricted use, distribution, and reproduction in any medium, provided the original author and source are credited. 
Citation: Basera TJ, Takuva S, Muloongo K, Tshuma N, Nyasulu PS (2016) Prevalence and Risk Factors for Self-reported Sexually Transmitted Infections among Adults in the Diepsloot Informal Settlement, Johannesburg, South Africa. J AIDS Clin Res 7: 539. doi:10.4172/21556113.1000539

Page 2 of 5

Physical and sexual intimate partner violence has also been found to be associated with increasing risk of STIs and HIV among women [10]. Epidemiological studies in informal settlements, have shown that people living in urban informal settlements have earlier sexual debuts, more sexual partners, are more likely to use alcohol, and are less likely to adopt preventive measures against contracting STIs compared with urban residents in formal settings [9,11]. In this study, we set to determine the prevalence of self-reported STIs and their associated factors among adults in Diepsloot, an informal settlement in Johannesburg.

\section{Methods}

\section{Study design}

This was a cross sectional study involving secondary analysis of data from the Community AIDS Response (CARe) community survey conducted in 2013 among 3953 participants residing in Diepsloot, Johannesburg. An initial sample of 400 dwellings was randomly selected using a table of random numbers and town planning maps of the study area. Among these 360 met the inclusion criteria constituting the final sample of 3953 respondents. The study population comprises respondents and other members of the selected primary households. Survey participants were 20 years or older and were recruited through household visits. Data from all the 3953 respondents were included for analysis. Ethical approval was obtained from the Monash University Human Research Ethics Committee number: CF14/2721 - 2014001511.

\section{Study setting}

The primary study was conducted in ward 95 of Diepsloot, an informal settlement located in in the extreme North of the City of Johannesburg Metropolitan Municipality located in the Gauteng Province, South Africa. Diepsloot has a mixture of informal and formal settlements. The township has a population of over 200000 people. The population is predominantly black and largely of low socio-economic status with over $50 \%$ of its residents being unemployed [12]. Prevalence of HIV in 2012 in Diepsloot was reported to be between 20\% and 40\%, compared to $11.1 \%$ in the City of Johannesburg Metro [13].

\section{Measurements}

The CARe community health profiling questionnaire collected data on socio-economic status, housing conditions, health status, access to health services and other behavioural factors. All measures in the primary study were self-reported. Questionnaires were administered to suitable respondents (persons of at least 18 years of age, who knew the most about the health of the members of the household) following written, informed consent at the selected dwellings. Interviews were conducted by data collectors who had been trained in interviewing techniques. The outcome variable was self-reported sexually transmitted infection among adults aged 20-82 years. In the Case survey, respondents were asked to report whether they have had any STI. The responses were coded as binary $(0=$ did not report an STI and $1=$ reported an STI).

The independent variables included: socio-demographic factors such as sex (male or female); age-group; marital status (single, married, cohabitating), employment status (unemployed, employed) and alcohol use. Age was recoded into 3 categories 20-29 years, 30-39 years and $\geq 40$ years. Marital status was recoded into three categories ( $1=$ Married, $2=$ single/divorced, $3=$ Cohabiting). Alcohol use was recoded into $\mathrm{No}=1$ and Yes $=2$. Health related information was collected for HIV seropositive status, ART treatment status, rate of health care utilisation and prior exposure to gender-based violence (GBV or sexual assault) defined as a pattern of abusive behaviour within the home, typically involving the violent abuse of a spouse or partner and sexual assault includes rape and other forms of unwanted penetration of the body.

\section{Data analysis}

For the descriptive data analysis, we summarised continuous variables as medians with interquartile ranges (IQRs) and categorical variables as percentages. Socio-demographic and clinical characteristics of participants were compared using the Pearson's Chi-square test. Logistic regression was performed to identify factors associated with reporting a sexually transmitted infection. Variables significant at the $10 \%$ level and those known a priori from the literature were considered for inclusion in multivariable models. All p-values reported are two tailed and $\mathrm{p}<0.05$ was considered statistically significant. STATA release 13 (Stata Corp., College Station, Texas, USA) was used for the analysis.

\section{Results}

\section{Characteristics of study participants}

Table 1 shows the socio-demographic and clinical characteristics of survey participants in Diepsloot. A total of 3953 participants, 20 years and older were included in the analysis. The majority were women, 2481(62.8\%). Most of the survey participants were between 20-29 years of age $(n=1873,47.4 \%)$ and $60.2 \%$ were cohabitating $(n=2378)$. In addition, most of the participants were unemployed $(n=3235,81.8 \%)$, and they used alcohol $(\mathrm{n}=2728,69 \%)$. Overall, $815(20.6 \%)$ people were HIV positive and among the HIV positive participants, $64 \%$ were not yet eligible for ART ( $\mathrm{n}=522$ ). Among the survey participants, 252 (6.4\%) reported exposure to gender based violence or sexual assault.

\section{Prevalence of STIs}

The main socio-demographic and clinical characteristics stratified by STI status are shown in Table 2. Overall, 1 in 5 people $(20.4 \%)$ reported an STI. Reporting an STI varied significantly by marital status $(\mathrm{p}=0.01)$, employment status $(\mathrm{p}=0.01)$, alcohol use $(\mathrm{p}=0.04)$, ART status $(\mathrm{p}=0.02)$, rate of healthcare utilisation $(\mathrm{p}<0.001)$ and prior exposure to gender based violence or sexual assault $(\mathrm{p}<0.001)$.

\begin{tabular}{|l|l|c|c|}
\hline \multicolumn{2}{|c|}{ Variable } & N & $\%$ \\
\hline Age & $20-29$ & 1873 & 47.4 \\
& $30-39$ & 1345 & 34.0 \\
\hline Sex & $40+$ & 735 & 18.6 \\
\hline Marital status & Male & 1472 & 37.2 \\
& Female & 2481 & 62.8 \\
\hline Employment status & Single & 738 & 18.7 \\
& Married & 837 & 21.2 \\
\hline Alcohol use & Cohabiting & 2378 & 60.1 \\
\hline Victim of Gender based violence/ & Employed & 718 & 18.2 \\
\hline Sexual assault & Unemployed & 3235 & 81.8 \\
\hline Health care visits & No & 1225 & 31.0 \\
& Yes & 2728 & 69.0 \\
\hline HICtim & 252 & 6.4 \\
\hline NiV status & At least once a month & 3701 & 93.6 \\
\hline ART status & At least once a year & 1160 & 29.3 \\
& Never in past 2 years & 813 & 50.1 \\
\hline & Positive & 815 & 20.6 \\
\hline & Negative & 3138 & 79.4 \\
\hline & On ART & 83 & 10.2 \\
\hline & Not yet eligible & 522 & 64.0 \\
\hline & No access to ART & 210 & 25.8 \\
\hline
\end{tabular}

Table 1. Socio-demographic and clinical characteristics of the sample used in this study. 
Citation: Basera TJ, Takuva S, Muloongo K, Tshuma N, Nyasulu PS (2016) Prevalence and Risk Factors for Self-reported Sexually Transmitted Infections among Adults in the Diepsloot Informal Settlement, Johannesburg, South Africa. J AIDS Clin Res 7: 539. doi:10.4172/21556113.1000539

Page 3 of 5

\begin{tabular}{|c|c|c|c|c|c|}
\hline \multirow{2}{*}{\multicolumn{2}{|c|}{ Variable }} & \multirow{3}{*}{$\begin{array}{c}\text { Total } \\
1873(47.4) \\
1345(34.0) \\
735(18.6)\end{array}$} & \multicolumn{2}{|c|}{ Reported STI } & \multirow{3}{*}{$\begin{array}{c}\text { p-value } \\
0.60\end{array}$} \\
\hline & & & \multirow{2}{*}{$\begin{array}{c}\text { Yes: Number (\%) } \\
373(19.9) \\
287(21.3) \\
148(20.1)\end{array}$} & \multirow{2}{*}{$\begin{array}{c}\text { No: Number (\%) } \\
1500(80.1) \\
1058(78.7) \\
587(79.9)\end{array}$} & \\
\hline Age & $\begin{array}{c}20-29 \\
30-39 \\
40+\end{array}$ & & & & \\
\hline Sex & $\begin{array}{l}\text { Male } \\
\text { Female }\end{array}$ & $\begin{array}{l}1472(37.2) \\
2481(62.8)\end{array}$ & $\begin{array}{l}310(21.1) \\
498(20.1)\end{array}$ & $\begin{array}{l}1162(78.9) \\
1983(79.9)\end{array}$ & 0.46 \\
\hline Marital status & $\begin{array}{c}\text { Single } \\
\text { Married } \\
\text { Cohabiting }\end{array}$ & $\begin{array}{c}738(18.7) \\
837(21.2) \\
2378(60.2)\end{array}$ & $\begin{array}{l}180(24.4) \\
155(18.5) \\
473(19.9)\end{array}$ & $\begin{array}{c}558(75.6) \\
682(81.5) \\
1905(80.1)\end{array}$ & 0.01 \\
\hline Employment status & $\begin{array}{l}\text { Employed } \\
\text { Unemployed }\end{array}$ & $\begin{array}{c}718(18.2) \\
3235(81.8)\end{array}$ & $\begin{array}{l}174(24.2) \\
634(19.6)\end{array}$ & $\begin{array}{c}544(75.8) \\
2601(80.4)\end{array}$ & 0.01 \\
\hline Alcohol use & $\begin{array}{l}\text { No } \\
\text { Yes }\end{array}$ & $\begin{array}{l}1225(39.0) \\
2728(69.0)\end{array}$ & $\begin{array}{l}274(22.4) \\
534(19.6)\end{array}$ & $\begin{array}{c}951(77.6) \\
2194(80.4)\end{array}$ & 0.04 \\
\hline Victim of Gender based violence/Sexual assault & $\begin{array}{l}\text { Victim } \\
\text { Not a victim }\end{array}$ & $\begin{array}{c}252(6.4) \\
3701(93.6)\end{array}$ & $\begin{array}{l}89(35.3) \\
719(19.4)\end{array}$ & $\begin{array}{c}163(64.7) \\
2982(80.6)\end{array}$ & $<0.001$ \\
\hline Health care utilisation & $\begin{array}{l}\text { At least once a month } \\
\text { At least once a year } \\
\text { Never in past } 2 \text { years }\end{array}$ & $\begin{array}{l}1160(29.3) \\
1980(50.1) \\
813(20.6)\end{array}$ & $\begin{array}{l}229(19.7) \\
369(18.6) \\
210(25.8)\end{array}$ & $\begin{array}{c}931(80.3) \\
1611(81.4) \\
603(74.2)\end{array}$ & $<0.001$ \\
\hline HIV status & $\begin{array}{c}\text { Positive } \\
\text { Negative }\end{array}$ & $\begin{array}{c}815(20.6) \\
3138(79.4)\end{array}$ & $\begin{array}{l}162(19.9) \\
646(20.6)\end{array}$ & $\begin{array}{l}653(80.1) \\
2492(79.4)\end{array}$ & 0.66 \\
\hline ART status & $\begin{array}{c}\text { On ART } \\
\text { Not yet eligible } \\
\text { No access to ART }\end{array}$ & $\begin{array}{c}83(7.0) \\
896(75.4) \\
210(17.7)\end{array}$ & $\begin{array}{c}20(24.1) \\
151(16.9) \\
23(11.0)\end{array}$ & $\begin{array}{c}63(75.9) \\
745(83.1) \\
187(89.0)\end{array}$ & 0.02 \\
\hline
\end{tabular}

Table 2. Socio-demographic and clinical characteristics of study participants by self-reported STI.

\begin{tabular}{|c|c|c|c|c|c|c|c|}
\hline \multicolumn{2}{|l|}{ Variable } & \multirow{2}{*}{$\begin{array}{c}\text { Unadjusted OR } \\
1 \\
1.09 \\
1.01\end{array}$} & \multirow{2}{*}{$\begin{array}{l}95 \% \mathrm{Cl} \\
0.92-1.30 \\
0.82-1.25\end{array}$} & \multirow{2}{*}{$\begin{array}{c}\text { p-value } \\
0.32 \\
0.90\end{array}$} & \multirow{2}{*}{\begin{tabular}{|c|} 
Adjusted OR \\
- \\
-
\end{tabular}} & \multirow{2}{*}{$\begin{array}{c}95 \% \mathrm{Cl} \\
- \\
-\end{array}$} & \multirow{2}{*}{$\begin{array}{c}\text { p-value } \\
- \\
-\end{array}$} \\
\hline Age & $\begin{array}{c}20-29 \\
30-39 \\
40+\end{array}$ & & & & & & \\
\hline Sex & $\begin{array}{l}\text { Male } \\
\text { Female }\end{array}$ & $\begin{array}{c}1 \\
0.96\end{array}$ & $0.80-1.10$ & 0.46 & - & - & - \\
\hline Marital status & $\begin{array}{l}\text { Married } \\
\text { Single } \\
\text { Cohabiting }\end{array}$ & $\begin{array}{c}1 \\
1.42 \\
1.09\end{array}$ & $\begin{array}{l}1.11-1.81 \\
0.89-1.34\end{array}$ & $\begin{array}{l}0.01 \\
0.39\end{array}$ & $\begin{array}{l}1.82 \\
1.39\end{array}$ & $\begin{array}{l}1.08-3.05 \\
0.90-2.15\end{array}$ & $\begin{array}{l}0.02 \\
0.14\end{array}$ \\
\hline Employment status & $\begin{array}{l}\text { Unemployed } \\
\text { Employed }\end{array}$ & $\begin{array}{c}1 \\
1.31\end{array}$ & $1.08-1.59$ & 0.01 & 1.36 & $0.89-2.06$ & 0.15 \\
\hline Alcohol use & $\begin{array}{l}\text { Non-drinker } \\
\text { Drinker }\end{array}$ & $\begin{array}{c}1 \\
0.84\end{array}$ & $0.72-1.00$ & 0.04 & 1.50 & $1.04-2.16$ & 0.03 \\
\hline Victim of Gender based violence/Sexual assault & $\begin{array}{l}\text { Not a Victim } \\
\text { Victim }\end{array}$ & $\begin{array}{c}1 \\
2.26\end{array}$ & $1.73-2.97$ & $<0.001$ & 2.25 & $1.39-3.63$ & 0.001 \\
\hline Health care visits & $\begin{array}{l}\text { At least once a month } \\
\text { At least once a year } \\
\text { Never in past } 2 \text { years }\end{array}$ & $\begin{array}{c}1 \\
0.93 \\
1.42\end{array}$ & $\begin{array}{l}0.78-1.12 \\
1.14-1.75\end{array}$ & $\begin{array}{c}0.45 \\
0.001\end{array}$ & $\begin{array}{l}1.43 \\
2.30\end{array}$ & $\begin{array}{l}0.96-2.13 \\
1.44-3.68\end{array}$ & $\begin{array}{c}0.08 \\
0.001\end{array}$ \\
\hline HIV status & $\begin{array}{l}\text { Positive } \\
\text { Negative }\end{array}$ & $\begin{array}{c}1 \\
1.04\end{array}$ & $0.86-1.22$ & 0.66 & 0.26 & $0.14-0.50$ & $<0.001$ \\
\hline ART status & $\begin{array}{c}\text { Not yet eligible } \\
\text { On ART } \\
\text { No access to ART }\end{array}$ & $\begin{array}{c}1 \\
1.57 \\
0.61\end{array}$ & $\begin{array}{l}0.92-2.77 \\
0.38-0.97\end{array}$ & $\begin{array}{l}0.10 \\
0.04\end{array}$ & $\begin{array}{l}1.36 \\
1.96\end{array}$ & $\begin{array}{l}0.78-2.35 \\
0.93-4.15\end{array}$ & $\begin{array}{l}0.28 \\
0.08\end{array}$ \\
\hline
\end{tabular}

Table 3. Binomial logistic regression of factors associated with self-reported STI.

Factors associated with self-reported STIs among the study population

The results of the univariable and multivariable logistic regressions of factors associated with self-reported STIs as the outcome variable are presented in Table 3. In univariable analyses the factors associated with reporting an STI were marital status $(\mathrm{p}=0.01)$, employment status $(\mathrm{p}=0.01)$, alcohol use $(\mathrm{p}=0.04)$, no access to ART $(\mathrm{p}=0.01)$, rate of utilisation of healthcare services $(\mathrm{p}<0.001)$ and being a victim of gender based violence or sexual assault $(\mathrm{p}=0.04)$.

In the multivariable analysis reporting an STI was associated with marital status, HIV status, rate of utilisation of healthcare services and prior exposure to gender based violence or rape. Reporting an STI was associated with being single [Odds Ratio $(\mathrm{OR})=1.82$, 95\% confidence interval (CI) 1.08, 3.05], alcohol use (OR 1.50, 95\% CI 1.04, 2.16),
HIV negative status (OR 0.26, 95\% CI 0.14, 0.50), having not utilised healthcare services in the past 2 years (OR 2.30, 95\% CI 1.44, 3.68) and having a history of gender based violence or rape (OR 2.25, 95\% CI 1.39, 3.63). However, employment status, and ART status had no significant association with reporting an STI.

\section{Discussion}

The study aimed to determine the prevalence and associated factors for self-reported STIs among adults in Diepsloot, Johannesburg. Our results show that one in five (20.4\%) adults in Diepsloot settlement reported an STI. These findings are important because STIs are a hidden epidemic and without integrating STI and HIV services, there will be limited success in controlling STIs. The prevalence of self-reported STIs was higher than regional estimates. For instance, a study in South Africa reported an STI prevalence of $13 \%$ among women [14] and a 
Citation: Basera TJ, Takuva S, Muloongo K, Tshuma N, Nyasulu PS (2016) Prevalence and Risk Factors for Self-reported Sexually Transmitted Infections among Adults in the Diepsloot Informal Settlement, Johannesburg, South Africa. J AIDS Clin Res 7: 539. doi:10.4172/21556113.1000539

Page 4 of 5

prevalence of $11 \%$ was reported among youths in Malawi [15], whereas a prevalence of $12 \%$ was reported among Ghanaian women [16].

Among HIV positive people we found $19.9 \%$ self-reported a prior STI, higher than the estimate of $16.3 \%$ in a systematic review of studies on STIs among people living with HIV [2]. If not addressed this population group is at risk of becoming even more affected. We found higher rates of self-reported STI (35.3\%) among those who had prior exposure to gender based violence or sexual assault.

In this study, we found being single, alcohol use, HIV status, prior exposure to gender based violence or sexual assault and having never utilised healthcare services in the past 2 years to have significant association with reporting STIs. Evidence from studies undertaken in Zimbabwe [8], Malawi [15] and Ghana [16], showed the same risk factors associated with self-reported STIs. Kalichman and Simbayi [17], observed that people who reported STIs were more likely to have a history of gender based violence Another study in South Africa also showed that intimate partner violence increase risk of incident HIV infection in young South African women [18]. Qualitative research has shown that the links between STIs including HIV and gender based violence lie in the patriarchal nature of society and ideals of masculinity that are based on control of women which readily translates into risky sexual behaviours [19]. Studies in South Africa [14], Mozambique [20] and New Caledonia [21] reported that being single was associated with STI acquisition.

Alcohol use increased the likelihood of reporting an STI. Similarly a systematic review of research conducted in Africa confirms an association between alcohol use and sexual risk for STIs [17]. Alcohol consumption has a disinhibiting effect that may make sexual risk behaviours and disease transmission more likely [17]. Never utilising healthcare services in the past 2 years was associated with self-reported STI. Poor health seeking behaviour which translates to non-utilisation of STI diagnosis and treatment services in primary care increases the likelihood of poor sexual health outcomes given that most STIs are asymptomatic [22].

The very strong association between HIV and reporting an STI was confirmed. Being HIV negative was negatively associated with reporting an STI, providing further evidence for the relation between STIs and HIV. Similar findings were reported in studies conducted in South Africa [23] and Spain [24]. The comorbidity of STIs and HIV emphasizes the need to address HIV testing among patients presenting with STIs [23]. We found no association between ART use and reporting STIs. The findings concerning ART use were consistent with findings from other studies, where ART use was associated with reduced risky sexual behaviour [25-27]. In a prospective cohort study undertaken in Uganda data from 926 HIV-infected adults showed that risky sexual behaviour reduced by $70 \%$ six months following ART initiation [28]. This has been linked to prevention counselling and partner voluntary counselling and testing $[25,28,29]$.

Despite finding low rates of STI among HIV-infected adults receiving ART, many participants reported an STI and hence the potential risk for HIV and STI transmission persists. It is important that STI and HIV prevention programs encourage condom use among HIVinfected people even after initiating ART. No associations between selfreported STI acquisition and age, gender, and employment status were observed, although these were identified as risk factors in other studies $[2,6,25]$. Several factors may explain these findings. Socio-demographic and behavioural characteristics of our study sample may be different to that in studies which reported significant associations. Our sample may represent a group with lower risk of STI acquisition. A survey on socio-demographic risk factors for STIs found that being from a young age group (18-25 years) was associated with STIs [21]. Similarly, a study that assessed unprotected sexual practices with HIV transmission risks found that STIs significantly occurred more for women [30].

\section{Limitations of the Study}

Our study may be limited by misclassification and findings may not be generalizable to the wider population due to possible differences in socio-demographic and behavioural characteristics of our sample to that of the wider population. Firstly, self-report of health conditions such as STIs is likely to be an underestimate of the actual prevalence due to social acceptability bias in interviews during the primary survey. STIs and HIV infections are very sensitive among community members as such individuals do not always feel free to talk about such issues to others. This might have led to an underestimation of self-reported STIs. Moreover, some important factors were not assessed, like risky sexual behaviours, condom use, number of sexual partners, type of STI, and sexual orientation. These unmeasured factors may give equally plausible contributing explanations. The cross sectional nature of the primary survey does not allow for proper ascribing of causality and associations between explanatory variables and STIs. It is difficult to ascertain for example whether STIs preceded HIV infection or vice versa. In addition information bias due to lack of adequate knowledge of STIs symptoms might have led to an underestimation of self-reported STIs while presence of asymptomatic STIs might have decreased the actual prevalence of self-reported STIs in this sample population. Lastly procedure for selection of the study participants might have introduced bias in the study, presuming that those not selected into the study might have self-reported STIs differently. This limitation was however minimised due to random nature of the sampling procedures.

\section{Conclusion}

Significant proportions of sexually active adults were found to have STIs. This study also found a high prevalence of HIV and that a high proportion of HIV-infected adults in the study population were not receiving HIV treatment in Diepsloot, Johannesburg. Having prior exposure to gender based violence, alcohol use, being HIV positive and non-utilisation of health services in the past 2 years were significantly associated with self-reported STI among adults in this study population. Findings indicate the need for integrated sexual health promotion, sexual health screening, and violent promotion efforts as well as encouraging better health seeking behaviours.

\section{Acknowledgements}

The authors would like to thank CARE International South Africa-Lesotho office for the financial support for primary data collection of the Integrated HIV and AIDS Prevention and Care project.

\section{Ethical Considerations}

Approval to use data for this study was obtained from Community AIDS Response (CARe). Informed consent from individual participants was obtained at the time of primary data collection, no participant identifiers were obtained. The study was approved by the Monash University ethics committee number: CF14/2721 - 2014001511

\section{References}

1. World Health Organization (2013) World Health Statistics, Geneva.

2. Kalichman SC, Pellowski J, Turner C (2011) Prevalence of sexually transmitted co-infections in people living with HIVIAIDS: systematic review with implications for using HIV treatments for prevention. Sex Transm Infect 87: 183-190.

3. National Strategic Plan for HIV and AIDS, STIs and TB, 2012-2016 (2012) National Department of Health, South Africa: Pretoria. 
Citation: Basera TJ, Takuva S, Muloongo K, Tshuma N, Nyasulu PS (2016) Prevalence and Risk Factors for Self-reported Sexually Transmitted Infections among Adults in the Diepsloot Informal Settlement, Johannesburg, South Africa. J AIDS Clin Res 7: 539. doi:10.4172/21556113.1000539

Page 5 of 5

4. Sexton J, Garnett G, Røttingen JA (2005) Metaanalysis and metaregression in interpreting study variability in the impact of sexually transmitted diseases on susceptibility to HIV infection. Sex Transm Dis 32: 351-357.

5. Johnson LF, Dorrington RE, Bradshaw D, Coetzee DJ (2012) The role of sexually transmitted infections in the evolution of the South African HIV epidemic. Trop Med Int Health 17: 161-168.

6. Kalichman SC, Simbayi LC, Cain D (2009) HIV transmission risk behaviours among HIV seropositive sexually transmitted infection clinic patients in Cape Town, South Africa. European Journal of Public Health 20: 202-206.

7. Aral SO, Over M, Manhart L, Holmes KK (2006) Disease Control Priorities in Developing Countries (2nd edition) Sexually Transmitted Infections Washington (DC): World Bank.

8. Chadambuka A, Chimusoro A, Maradzika JC, Tshimanga M, Gombe NT, et al. (2011) Factors associated with contracting sexually transmitted infections among patients in Zvishavane urban, Zimbabwe; 2007. African Health Sciences 11: $535-542$

9. Ragnarsson A, Ekström AM, Carter J, Ilako F, Lukhwaro A, et al. (2011) Sexua risk taking among patients on antiretroviral therapy in an urban informal settlement in Kenya: a cross-sectional survey. Journal of the International AIDS Society 14: 20-29.

10. Rahman M, Nakamura K, Seino K, Kizuki M (2014) Intimate partner violence and symptoms of sexually transmitted infections: are the women from low socio-economic strata in Bangladesh at increased risk. Int $\mathrm{J}$ Behav Med 21: 348-357.

11. Zulu EM, Dodoo FN, Chika-Ezee A (2002) Sexual risk-taking in the slums of Nairobi, Kenya, 1993-8. Popul Stud (Camb) 56: 311-323.

12. Statistics South Africa (2013) Census 2011 Fact Sheet, South Africa.

13. Human Sciences Research Council (2014) South African National HIV Prevalence, Incidence and Behaviour Survey, 2012.

14. Naidoo S, Wand H, Abbai NS, Ramjee G (2014) High prevalence and incidence of sexually transmitted infections among women living in Kwazulu-Natal, South Africa. AIDS Res Ther 11: 31

15. N WC, A S (2015) Associated Risk Factors of STls and Multiple Sexual Relationships among Youths in Malawi. PLoS One 10: e0134286.

16. Ohene S, Akoto I (2008) Factors associated with sexually transmitted infections among young ghanaian women. Ghana Med J 42: 96-100.

17. Kalichman SC, Simbayi LC, Kaufman M, Cain D, Jooste S (2007) Alcohol use and sexual risks for HIVIAIDS in sub-Saharan Africa: systematic review of empirical findings. Prev Sci 8: 141-151.

18. Jewkes RK, Dunkle K, Nduna M, Shai N (2010) Intimate partner violence, relationship power inequity, and incidence of HIV infection in young women in South Africa: a cohort study. Lancet 376: 41-48.

19. García-Moreno C, Watts C (2000) Violence against women: its importance for HIVIAIDS. AIDS 14 Suppl 3: S253-265.

20. Men'endez C, Castellsagu'e X, Renom M, Sacarlal J, Quintó L, et al. (2010) Prevalence and Risk Factors of Sexually Transmitted Infections and Cervical Neoplasia in Women from a Rural Area of Southern Mozambique. Infectious Diseases in Obstetrics and Gynecology pp: 1-10.

21. Corsenac P, Noël M, Rouchon B, Hoy D, Roth A (2015) Prevalence and sociodemographic risk factors of chlamydia, gonorrhoea and syphilis: a national multicentre STI survey in New Caledonia, 2012. BMJ Open 5: e007691.

22. Fenton KA, Mercer CH, Johnson AM, Byron CL, McManus S, et al. (2005) Reported Sexually Transmitted Disease Clinic Attendance and Sexually Transmitted Infections in Britain: Prevalence, Risk Factors, and Proportionate Population Burden. The Journal of Infectious Diseases 191: 127-138.

23. Mhlongo S, Magooa P, Muller EE, Nel N, Radebe F, et al. (2010) Etiology and STI/HIV Coinfections Among Patients With Urethral and Vaginal Discharge Syndromes in South Africa. Sexually Transmitted Diseases 37: 566-570.

24. Ariza-Mejía MC, García-García L, Puerta-López T, Menéndez-Prieto B, VeraGarcía M, et al. (2013) Risk Factors of HIV Co-Infection and Sexual Behaviours in Patients with Gonococcal Infection in a STI's Clinic in Madrid. J AIDS Clin Res 4: $240-245$

25. Wang XB, Tucker JD, Yang L, Zheng H, Zhang F, et al. (2013) Unsafe sex and STI prevalence among HIV infected adults in Guangzhou, China: Opportunities to deamplify sexual HIV transmission. AIDS Behav 17: 1137-1143.

26. Sarna A, Luchters S, Pickett M, Chersich M, Okal J, et al. (2012) Sexua behavior of HIV-positive adults not accessing HIV treatment in Mombasa, Kenya: Defining their prevention needs. AIDS Res Ther 9: 9.

27. Venkatesh KK, de Bruyn G, Lurie MN, Mohapi L, Pronyk P, et al. (2010) Decreased sexual risk behavior in the era of HAART among HIV-infected urban and rural South Africans attending primary care clinics. AIDS 24: 2687-2696.

28. Bunnell R, Ekwaru JP, Solberg P, Wamai N, Bikaako-Kajura W, et al. (2006) Changes in sexual behavior and risk of HIV transmission after antiretroviral therapy and prevention interventions in rural Uganda. AIDS 20: 85-92.

29. Apondi R, Bunnell R, Ekwaru JP, Moore D, Bechange S, et al. (2011) Sexual behavior and HIV transmission risk of Ugandan adults taking antiretroviral therapy: 3 year follow-up. AIDS 25: 1317-1327.

30. Engedashet E, Worku A, Tesfaye G (2014) Unprotected sexual practice and associated factors among People Living with HIV at Antiretroviral Therapy clinics in Debrezeit Town, Ethiopia: across sectional study. Reproductive Health 11: $56-65$. 